\title{
Cephalic Tetanus without Injury - A Rare Presentation of Tetanus
}

\author{
Ramanan B.B.V.1 , Ajit Kumar Pegu' ${ }^{2}$ Anupam Dutta ${ }^{3}$, Arjit Das4, Sanchu T.K. Sreeraj ${ }^{5}$ \\ 1,2,3,4,5 Department of General Medicine, Assam Medical College \& Hospital, Dibrugarh, Assam, India.
}

\section{INTRODUCTION}

Tetanus is a rare, severe, and potentially life-threatening disease caused by Clostridium tetani, which accounted 58,900 deaths worldwide in 2013. ${ }^{1}$ Usually tetanus is generalized, rarely it can be localized also. $20-30 \%$ of cases will not have any puncture wound. In this case report, we present a case of tetanus with rare manifestation (localized tetanus presented with trismus without any puncture wound). Multiple rare associations like tetanus presenting with trismus, tetanus occurring in the absence of puncture wound strengthens the need for reporting this case which if left unnoticed would have been detrimental to the patient.

\section{PRESENTATION OF CASE}

A 65-year-old female patient came to the casualty of our hospital with complaints of difficulty in swallowing for both liquids and solids since 10 days for which she had been evaluated in a local hospital and referred to our hospital for further management. On elaborating, there was no history of painful swallowing, vomiting, regurgitation, heartburn, loss of weight and appetite. She also had history of difficulty in opening mouth, chewing, slurring of speech, spasm of neck muscles and inability to lie in supine position. There was no history of trauma. There were no significant co-morbidities in the past. She was a tobacco chewer and smoker for 25-30 years.

On examination, she was conscious, alert, cooperative, oriented to time, place and person, thin built. No wound or scar noticed. Level of consciousness, behaviour, memory, and intelligence were within normal limits. Speech was dysarthric. Cranium was normal and kyphosis was present. Neck rigidity and Kernig's sign were absent. Cranial nerve examination revealed difficulty in opening mouth, difficulty in mastication, exaggerated jaw jerk, difficulty in swallowing, absent gag reflex, difficulty in protruding tongue, difficulty in speech and stiffness of neck muscles. Other cranial nerve examinations were normal. Motor system examination revealed normal bulk, tone, power and co-ordination. There were no involuntary movements. Deep tendon reflexes and superficial reflexes were normal. Plantar response was flexor on both sides. Sensory system examination was normal. Cerebellar system examinations were insignificant. Bowel and bladder habits were normal. No abnormality in gait was found. Cardiovascular, respiratory, and gastrointestinal system examination did not reveal any significant findings.

Blood investigations showed mild neutrophilia, while electrolytes, renal function test, liver function test, thyroid function test, random blood sugar were normal. Upper GI endoscopy revealed pan gastritis, CT Neck and CT Brain were insignificant.

\begin{tabular}{|cccc|}
\hline Parameters & Value & Parameters & Value \\
Hb & $10 \mathrm{gm} / \mathrm{dl}$ & Total bilirubin & $1.46 \mathrm{mg} / \mathrm{dl}$ \\
ESR & $20 \mathrm{~mm} / \mathrm{hr}$ & Total protein & $6.16 \mathrm{mg} / \mathrm{dl}$ \\
WBC & $14,200 /$ cu.mm & Albumin & $3.75 \mathrm{mg} / \mathrm{dl}$ \\
Platelet & 1.4 lakh / cu.mm & Globulin & $2.41 \mathrm{mg} / \mathrm{dl}$ \\
RBC & $3.6 \mathrm{million} / \mathrm{cu} . \mathrm{mm}$ & ALT & $23 \mathrm{U} / \mathrm{L}$ \\
PCV & $31.5 \%$ & AST & $120 \mathrm{U} / \mathrm{L}$ \\
MCV & $86.5 \mathrm{fl}$ & ALP & $62 \mathrm{U} / \mathrm{L}$ \\
MCH & $27.5 \mathrm{pg}$ & GGT & $14 \mathrm{U} / \mathrm{L}$ \\
MCHC & $31.7 \mathrm{gm} \mathrm{/} \mathrm{dl}$ & RBS & $89 \mathrm{mg} / \mathrm{dl}$ \\
Blood urea & $21 \mathrm{mg} / \mathrm{dl}$ & Serum creatinine & $0.9 \mathrm{mg} / \mathrm{dl}$ \\
Sodium & $137 \mathrm{mmol} / \mathrm{hr}$ & Calcium & $8.1 \mathrm{mg} / \mathrm{dl}$ \\
Potassium & $4 \mathrm{mmol} / \mathrm{hr}$ & TSH & $4.30 \mathrm{mu} / \mathrm{l}$ \\
\hline \multicolumn{4}{c}{ Table 1. Investigations } \\
\hline
\end{tabular}

Corresponding Author: Dr. Ramanan $B B V$,

Department of General Medicine, Assam Medical College \& Hospital, Dibrugarh, Assam, India.

E-mail: ramananfurious12@gmail.com

DOI: $10.14260 / \mathrm{jemds} / 2021 / 324$

How to Cite This Article:

Ramnan BBV, Pegu AK, Dutta A, et al. Cephalic tetanus without injury - a rare presentation of tetanus. J Evolution Med Dent Sci 2021;10(20):1555-1557, DOI: 10.14260/jemds/2021/324

Submission 08-01-2021,

Peer Review 18-03-2021,

Acceptance 24-03-2021,

Published 17-05-2021.

Copyright (C) 2021 Ramanan B.B.V. et al. This is an open access article distributed under Creative Commons Attribution License [Attribution 4.0 International (CC BY 4.0)] 


\section{DISCUSSION OF MANAGEMENT}

Neurology consultation and ENT consultation were taken and was planned for MRI brain and MRI TM joint. MRI brain and MRI TM joint were insignificant. During day 2 of hospital stay, we noticed intermittent spasm of neck muscles not associated with generalized jerky movement and loss of consciousness. Upon strong clinical suspicion, we immediately started Inj. Tetanus toxoid, Inj. Tetanus immunoglobulin, Injectable antibiotics (Metronidazole) and muscle relaxants. Patient showed drastic improvement of symptoms and was discharged home after 5 days of observation.

Patient was reviewed back after 15 days in medicine outpatient department. She had clinically improved and could eat orally.

\section{DISCUSSION}

Tetanus is a rare, life threatening disease with fatal outcome if not detected and treated early. In developed countries, it is well controlled due to active vaccination with only 233 cases reported in United States between 2001 and 2008. ${ }^{2}$

Only 6 cases reported in UK in 2013. ${ }^{3}$ It is an infection found predominantly in tropical countries.

Tetanus is caused by a rod shaped, spore forming and gram positive, anaerobic bacterium Clostridium tetani. ${ }^{4}$ The spores are highly resilient and readily survive in the environment. It is found in soil and gastrointestinal tracts of mammals. Transmission of host occurs usually through cut wounds, abrasions in the skin following an injury. 25-30\% of cases occur without any wound.5,6 In a suitable anaerobic environment, the bacteria grow, multiplies and releases toxin. Incubation period ranges from 3 days to 3 weeks. The toxin is a potent neurotoxin called tetanospasmin which enters the central nervous system and inhibits the release of gamma aminobutyric acid (GABA), an inhibitory neurotransmitter acting on motor neurons. Minimum lethal human dose is 2.5 $\mathrm{ng} / \mathrm{kg}$. Tetanus can manifest as a generalized or local form. Majority of the cases in clinical practice are generalized form which is far more common than local forms. However, rare, atypical forms of tetanus like cephalic tetanus, neonatal tetanus and localized tetanus have also been reported. Among the atypical presentation, cephalic tetanus is least common (1$3 \%) .^{7}$

Cephalic tetanus presents with dysphagia, trismus, risus sardonicus, gaze deviation, eyelid retraction, mostly involving the bulbar muscles. ${ }^{8}$ Cephalic tetanus can later progress to generalized tetanus resulting in death.

Diagnosis is clinical as there is no laboratory tool for confirmation. ${ }^{9}$ Treatment involves debridement of wound, injectable antibiotics to decrease the bacterial load, metronidazole is found to be efficacious in few studies compared to penicillin group of drugs, as penicillin group of drugs itself can cause inhibitory effect on neuromuscular junction aggravating the disease. ${ }^{10}$ Administration of tetanus immunoglobulin 3000-5000 IU I.M will decrease the mortality to greater extent, especially in generalized tetanus. Tetanus vaccination should be given at the time of presentation and one month later to strengthen the immunity, 11 as tetanus toxin is poorly immunogenic and the immune response following natural infection is inadequate.
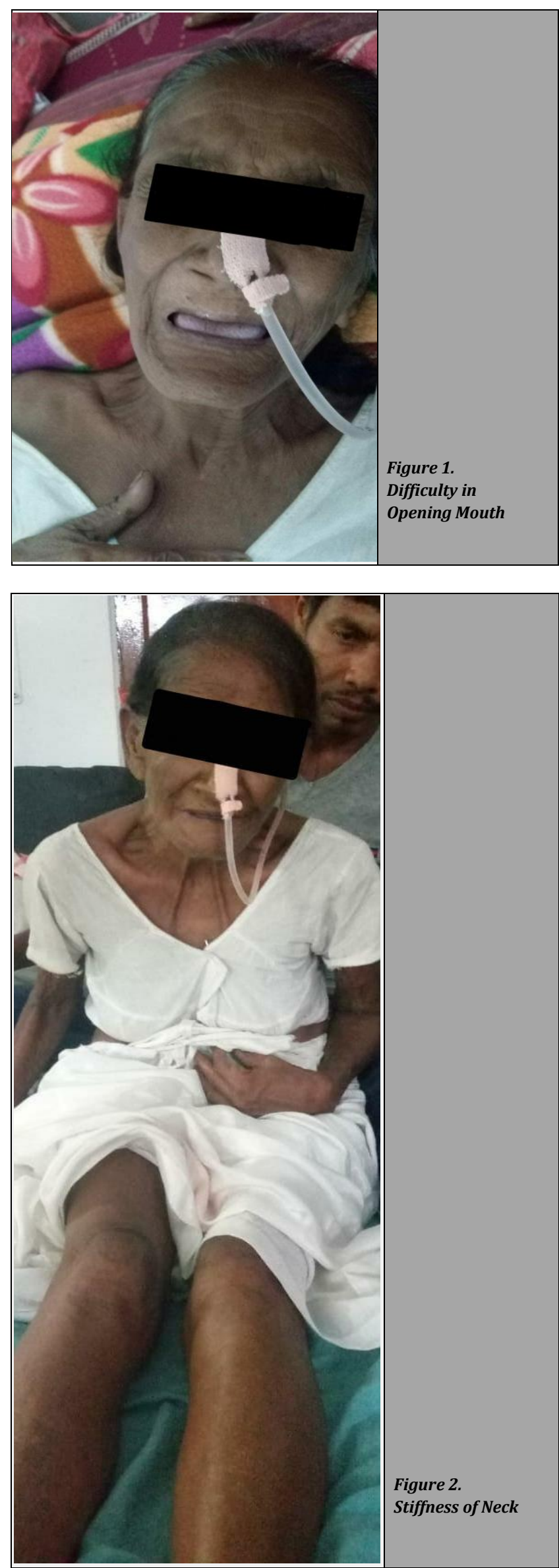


\section{CONCLUSIONS}

The patient presented above was an elderly woman, susceptible to acquire tetanus because of her inadequate vaccination status. She presented with typical symptoms of atypical form of a rare disease in the current era and has been overlooked for the same reason. The above case illustrates the importance of early recognition of all forms of tetanus, strong clinical suspicion in making the diagnosis and timely administration of treatment which is life saving for the patient and also reminds us the importance of adequate vaccination for tetanus being the most important preventive measure against tetanus.

Financial or other competing interests: None.

Disclosure forms provided by the authors are available with the full text of this article at jemds.com.

\section{REFERENCES}

[1] GBD 2013 Mortality and Causes of Death Collaborators. Global, regional and national age-sex specific all-cause and cause-specific mortality for 240 causes of death, 1990-2013: a systematic analysis for the global burden of disease study 2013. Lancet 2015;385(9963):117-71.

[2] Centre for Disease Control and Prevention. Tetanus surveillance---United States 2001-2008. Morbidity and Mortality weekly Report 2011;60(12):365-9.
[3] Public Health. Infection Report/Immunisation. Tetanus in England and Wales 2014. England: Health Protection Report 2015;9(18).

[4] Campbell JI, Yen LT, Loan HT, et al. Microbiologic characterization and antimicrobial susceptibility of clostridium tetani isolated from wounds of patients with clinically diagnosed tetanus. Am J Trop Med Hyg 2009;80(5):827-31.

[5] Cook TM, Protheroe RT, Handel JM. Tetanus: a review of literature. Br J Anaesth 2001;87(3):477-87.

[6] Farrar JJ, Yen LM, Cook T. Tetanus. J Neurol Neurosurg Psychiatry 2000;69(3):292-301.

[7] Seo DH, Cho DK, Kwon HC, et al. A case of cephalic tetanus with unilateral ptosis and facial palsy. Ann Rehabil Med 2012;36(1):167-70.

[8] Gupta V, Dewangan S, Bhatia BD. Localised tetanus: rare presentation of a forgotten disease. J Paediatr Child Health 2011;47(3):152.

[9] Faulkner AE, Tiwari TSP. Tetanus. Chap. 16. VPD surveillance manual. Center for Disease Control and Prevention 2011:1-6.

[10] Ahmadsyah I, Salim A. Treatment of tetanus: an open study to compare the efficacy of procaine penicillin and metronidazole. $\mathrm{Br}$ Med J (Clin Res Ed) 1985;291(6496):648-50.

[11] Gulamhussein MA, Li Y, Guha A. Localized tetanus in an adult patient: case report. J Orthop Case Rep 2016;6(4):100-2. 